\title{
CONFLICTOS ENTRE LAS INDICACIONES DE ORIGEN GEOGRÁFICO Y LAS MARCAS EN EL DERECHO ARGENTINO
}

\section{CONFLICTS BETWEEN GEOGRAPHICAL DESIGNATIONS AND TRADEMARKS IN ARGENTINE LAW}

\author{
Marcela Sandra Molina*
}

\begin{abstract}
RESUMEN: La autora analiza los conflictos de las indicaciones de origen geográfico entre sí y estas y las marcas vigentes a la fecha en que entró en vigencia el Acuerdo ADPIC en la República Argentina. Particularmente, analiza la aplicabilidad o no de los principios del régimen marcario; también la existencia de principios específicos para las indicaciones de origen geográfico y los casos de coexistencia de signos distintivos previstos en dicho Acuerdo internacional y en la legislación argentina.
\end{abstract}

Palabras clave: Denominación de origen, indicación geográfica, marcas.

ABSTRACT: In this paper, the author analyzes conflicts between geographical indications and between them and trademarks. In particular, she analyzes the applicability of the principles of trademark law to appellations of origin and geographical indications, the specific rules for geographical indications and cases of coexistence of distinctive signs as established in the TRIPS Agreement and in Argentine law.

Key words: Appellation of origin, geographical indications, trademarks.

\section{INTRODUCCIÓN}

La denominación de origen (DO) ha sido incorporada como objeto de propiedad intelectual por el art. 1 del Convenio de París de 1883 (revisión de La Haya 1925). El Acuerdo sobre los Aspectos de los Derechos de Propiedad Intelectual relacionados con el Comercio (ADPIC) suscripto en Marrakech, Marruecos, el 15 de abril de 1994, incorporó a la indicación geográfica (IG).

En general, las indicaciones de origen geográfico son reconocidas sobre la base de las leyes y reglamentos aplicables en su territorio de origen. Algunos sistemas jurídicos las regulan como una categoría sui generis; otros dentro del régimen de marcas de certificación o colectiva, y otros aplican las normas de competencia desleal. Algunos lo incorporan al dominio público y otros en el régimen de patrimonio cultural inmaterial.

\footnotetext{
* Doctora en Ciencias Jurídicas por la Universidad de Mendoza. Instituto de Estudios de Derecho Administrativo, Provincia de Mendoza, Argentina. Dirección postal: 25 de mayo 945, $7^{\circ}$ piso, 2, Ciudad, Mendoza (5500), Argentina. Dirección electrónica: marcsmolina@yahoo.com.ar.
} 
En la República Argentina, la Ley N ${ }^{\circ} 17.011^{1}$ aprobó el Convenio de París de 1883. La Ley $\mathrm{N}^{\circ} 24.425^{2}$ aprobó el Acuerdo ADPIC.

Pocos años después, la Ley Nacional N²5.1633 reglamentó tres categorías de indicaciones de origen geográfico (indicación geográfica -IG-, indicación de procedencia -IP- y denominación de origen controlada -DOC-) para los vinos y bebidas espirituosas de origen vínico. La Ley $\mathrm{N}^{\circ} 25.380^{4}$ modificada por Ley $\mathrm{N}^{\circ} 25.966^{5}$, reguló la IG y DO para los demás productos agrícolas.

La aplicación de este régimen debió respetar los derechos marcarios adquiridos sobre topónimos a la fecha de aplicación del Acuerdo ADPIC. Estos signos distintivos se habían registrado conforme la jurisprudencia elaborada en torno a las sucesivas leyes de marcas.

¿Cómo se resuelven los conflictos entre sí de las indicaciones de origen geográfico, y entre estas y las marcas? ¿Qué camino han seguido los titulares o usuarios de DO nacionales y extranjeras?

Esos conflictos pueden llegar a ser complejos en relación a los vinos cuando contiene una IG o DO que integra una marca nacional o extranjera, especialmente si ambos son signos notorios; o en caso que coincidan con el nombre de una variedad de vid.

Los principios marcarios, particularmente de prioridad y especialidad ¿̇igen respecto de las designaciones de origen geográfico? ¿Cuáles son los principios específicos de las designaciones de origen geográfico?

En el presente trabajo examinamos cómo se resuelven los conflictos entre las marcas y las DO e IG en el derecho argentino, y los supuestos de coexistencia de signos distintivos. Particularmente, analizamos la aplicabilidad o no de los principios de prioridad legal y especialidad a la DO e IG, y la aplicabilidad o no de las reglas de las marcas notorias. Por último, examinaremos el principio de territorialidad y los acuerdos bilaterales y multilaterales tendientes a mejorar la protección de la DO e IG.

El significado y alcance de la DO e IG varía en los distintos ordenamientos jurídi$\cos ^{6}$. Por eso, aclaramos que, en este trabajo, utilizamos la expresión indicaciones de origen geográfico como término genérico que comprende las tres categorías: IG, IP y DO, según recomendaciones del Comité Permanente de la OMPI (SCT 8/5) 7 .

\footnotetext{
1 LEY N 17.011 de 1966.

2 LEY No 24.425 de 1995.

3 LEY $\mathrm{N}^{\circ} 25.163$ de 1999.

4 LEY $\mathrm{N}^{\circ} 25.380$ de 2001.

5 LEY N²5.966 de 2004.

6 En algunos documentos, el Comité de la OMPI se refirió a la IG como un término genérico comprensivo de la IP y DO (Documento SCT 5/3, 5a sesión del 11 al 15/9/00, parágrafo 16). En posteriores documentos, circunscribió el uso de la expresión IG a la significación específica del art. 22.1 del Acuerdo ADPIC utilizando la expresión indicaciones de origen geográfico como denominador común de todas las categorías.

7 Documento SCT 8/5, 8a sesión 27 al 31/5/2002, parágrafo 5 a 8. Disponible en: www.wipo.int. Consultado: 10 de octubre de 2016.
} 


\section{CARACTERÍSTICAS DE LAS INDICACIONES DE ORIGEN GEOGRÁFICO Y SUS DIFERENCIAS CON LAS MARCAS EN EL DERECHO ARGENTINO}

Las marcas y las indicaciones de origen geográfico son signos distintivos cuya perceptibilidad se manifiesta en dos sentidos: a) intrínseco, como aptitud identificatoria; b) extrínseco, como idoneidad del signo de diferenciarse de otros ya existentes ${ }^{8}$. En su condición de signos distintivos cumplen las siguientes funciones: identificación de los productos, garantía de calidad y protección del consumidor.

Estas similitudes podrían justificar a priori la aplicación de los principios de las marcas (principios de prioridad, especialidad, territorialidad) a las indicaciones de origen geográfico.

No obstante, estos signos distintivos presentan profundas diferencias ${ }^{9}$ en el derecho argentino, que deben tenerse en cuenta al momento de determinar la aplicación o no de los principios marcarios a las indicaciones de origen geográfico o la aplicación de principios específicos para estas últimas (como los principios de veracidad), y la admisión de la coexistencia de signos distintivos en ciertos casos.

Primero, las marcas identifican productos y servicios de una empresa. Las indicaciones de origen geográfico identifican productos de una zona geográfica pudiendo ser utilizadas por todos los productores de la región que se ajustan a las leyes y reglamentos internos; y se aplican exclusivamente a los vinos y a los productos agroalimentarios ${ }^{10}$. Excepcionalmente, la Legislatura de la Provincia de Misiones ${ }^{11}$ extendió este régimen a las artesanías aunque excediéndose en sus atribuciones constitucionales.

Segundo, las marcas pueden consistir en una o más palabras con o sin sentido conceptual, dibujos, emblemas, monogramas, grabados, estampados, sellos, imágenes y todo otro signo con capacidad distintiva. El derecho sobre la marca se adquiere mediante el registro en el INPI, previa acreditación de la capacidad distintiva y disponibilidad ${ }^{12}$.

En cambio, en el derecho argentino las tres categorías de indicaciones de origen geográfico (IP, IG y DO), deben estar conformadas necesariamente por un topónimo. En el derecho comparado se ha entendido que la definición del Acuerdo ADPIC permite "que sean considerados como IG no solo los nombres de los lugares de procedencia sino que también otro tipo de signos, abriendo entonces la puerta a casos como Cava, para el espumante español e incluso para signos de fantasía"13, siempre que evoquen el origen geográfico.

8 Otamendi (2002) pp. 107-110; Bertone y Cabanellas de las Cuevas (2003) pp. 346-350.

9 Pastorino (2005) pp. 182-183; Schiavone (2003) p. 22.

10 Otras legislaciones admiten la aplicación a artesanías y servicios como las LEYEs $\mathrm{N}^{\circ} 17.011$ (Uruguay) de 1998 y Nº 9.279 (Brasil) de 1996.

11 LEY No VIII-51 de 1996.

12 Bertone y Cabanellas de las Cuevas (2003) pp. 346-350.

13 Belmar Gamboa (2016) p. 256. 
La IG y DO (DOC para vinos) identifican un producto típico (aquel con cualidades peculiares que permiten discriminar el producto de otros similares $\left.{ }^{14}\right)$. Por eso, para su reconocimiento y protección deben acreditarse las características agroecológicas del área geográfica y renombre del producto originario. En la DO debe acreditarse además, los factores humanos que influyen en la tipicidad del producto.

Tercero, la marca y las indicaciones de origen geográfico son herramientas que tienen por fin atraer clientela orientándola a adquirir el producto. La marca tiene un valor inmaterial independiente del producto; es disponible y embargable. En cambio, la IG y DO tienen un valor en función de la calidad y tipicidad del producto. Ese valor es inseparable del producto y es inembargable.

Cuarto, el uso de la marca genera beneficios económicos a su titular, existiendo un mero interés privado. La IP (solo para vinos), IG y DO (DOC para vinos), trasciende el ámbito privado de cada usuario, generando beneficios económicos y sociales no solo a los productores sino a la región, promoviendo el desarrollo rural sostenible, el arraigo e integración vertical de agricultores, el ordenamiento territorial, y el envasado en origen. Además, cualquier uso indebido o fraudulento puede producir consecuencias perjudiciales no solo a los productores adheridos al sistema (por la merma de ventas) sino también puede afectar la economía local, especialmente aquellas regiones cuya estructura económica depende de un único producto agrícola.

Quinto, en la República Argentina la adquisición, conservación y extinción del derecho marcario está regulado por las Leyes $\mathrm{N}^{\circ} 22.362^{15}$ y $\mathrm{N}^{\circ} 22.802^{16}$; el derecho administrativo regula solo el procedimiento de registración. En caso de uso indebido por terceros, el titular debe efectuar la denuncia penal o iniciar las acciones de cese de uso y daños y perjuicios. En cambio, el reconocimiento de las indicaciones de origen geográfico, la concesión del derecho de uso y fiscalización de su funcionamiento ${ }^{17}$, está sujeto a un régimen esencialmente de derecho público en razón del interés público involucrado.

Sexto, la marca confiere a su titular un derecho de uso temporario. En el derecho argentino, la vigencia de la IP (solo para vinos) IG, y DO (DOC de vinos) es indefinida.

Séptimo, la marca se extingue por caducidad en caso de no uso por más de 5 años. El reconocimiento de una indicación de origen geográfico no se extingue por el no uso de los productores. Tampoco, el derecho de uso se extingue por el no uso.

\footnotetext{
14 Comité Permanente sobre Derechos de marcas, dibujos y modelos industriales e indicaciones geográFICAS, OMPI (2003): Documento SCT 10/4, parágrafo 28.

15 LEY N 22.362 de 1980.

16 LEY No 22.802 de 1983.

17 Comité Permanente sobre derecho de maras, dibujos y modelos industriales e indicaciones GeográfiCAS, OMPI (2002): Documento SCT 9/4, parágrafo 53.
} 


\section{LAS INDICACIONES DE ORIGEN GEOGRÁFICO (IG, DO) Y LAS MARCAS EN EL DERECHO ARGENTINO}

\subsection{LAS MARCAS Y LOS NOMBRES GEOGRÁFICOS EN LA REPÚBLICA ARGENTINA}

Las marcas registradas de buena fe a la fecha en que empezó a regir el Acuerdo ADPIC en la República Argentina, ha constituido un límite a la protección de IG y DO extranjeras, sin perjuicio de aquellas que podían invocar la protección dentro del marco del régimen de competencia desleal (Ley $\mathrm{N}^{\circ}$ 22.802).

Una peculiaridad del régimen marcario argentino es que en muchos casos las marcas están conformadas por nombres geográficos, coexistiendo algunos signos integrados por el mismo toponímico en distintas clases del Nomenclador de marcas, incluso en la misma clase. Estos nombres geográficos de provincias y localidades integran marcas donde el nombre geográfico es el elemento de uso común integrado por otro aditamento que torna al conjunto inconfundible. Algunos nombres geográficos han sido reconocidos y protegidos como IG o DO argentina (Patagonia, Luján, San Rafael, Mendoza para vinos; Tandil, Caroya para otros productos agrícolas) ${ }^{18}$.

Otros signos marcarios compuestos, están integradas por DO extranjeras en la misma clase 33 del Nomenclador (DO Toro, Rioja, Margaux, Lambrusco, etc. ${ }^{19}$ ), incluso hay numerosas marcas conformadas por DO extranjeras que han pasado a ser nombres genéricos en Argentina ${ }^{20}$ (Jerez, Oporto, Champagne, Tequila, Borgoña, Roquefort, Reggiano, etc.) $)^{21}$.

18 Se ha constatado que existen 1445 marcas registradas en varias clases del Nomenclador, conformadas por el nombre geográfico Patagonia como elemento nominal (5 están registradas en la clase 33). El topónimo Luján o Lujan conforma 130 marcas vigentes en varias clases del Nomenclador (4 en la clase 33, siendo el titular de una de ellas el Consejo de Promoción de la DOC Luján de Cuyo). El nombre geográfico San Rafael, integra 36 marcas vigentes pertenecientes a distintos titulares (tres en la clase 33, siendo titular de una de estas, el Consejo de DOC San Rafael). El topónimo Tandil y su gentilicio integra 191 marcas en varias clases del Nomenclador y pertenecientes a distintos titulares uno de cuyos titulares es la Municipalidad de Tandil. Por su parte, la designación Caroya integra 11 marcas pertenecientes a distintos propietarios (uno de los cuales es la Municipalidad de Caroya). La designación Mendoza, integra 509 marcas vigentes en varias clases del Nomenclador (26 en la clase 33). Varias marcas fueron registradas en décadas anteriores a la entrada en vigencia del Acuerdo ADPIC, siendo renovadas ininterrumpidamente. Datos extraídos de: www.inpi.gov.ar. Fecha de consulta: 15 de abril de 2016.

19 La designación Toro integra 307 marcas (26 registradas en la clase 33). El topónimo "Rioja" y su gentilicio integra 104 marcas como pertenecientes a distintos titulares y en distintas clases (24 registradas en la clase 33). La designación Margaux integra 3 marcas vigentes (dos en la clase 33). Por su parte, Lambrusco (DO extranjera) integra dos marcas en la clase 33. Varias marcas fueron registradas antes de la entrada en vigencia del Acuerdo ADPIC. Datos extraídos de: www.inpi.gov.ar. Fecha de consulta: 15 de abril de 2016.

20 Molina (2015) pp. 64-82.

21 La DO Jerez integra 5 marcas vigentes pertenecientes a distintos titulares en distintas clases ( 3 registradas en la clase 33, aunque en una época hubo casi 22 marcas integradas por el mismo topónimo). La DO Oporto integra 5 marcas pertenecientes a distintos titulares (1 en la clase 33). La DO Champagne integra 11 marcas en varias clases del Nomenclador y pertenecientes a distintos titulares ( 9 en la clase 33 pero hasta el año 2004 hubo alrededor de 36 marcas con la misma designación). La DO Borgoña integra 5 marcas en diferentes clases del Nomenclador, y 2 en la clase 33. La DO Tequila integra 11 marcas a nombre de varios titulares y en varias clases del Nomenclador (7 en la clase 33). Datos extraídos de: www.inpi.gov.ar. Fecha de consulta: 15 de abril de 2016 . 
El registro de marcas constituidas por nombres geográficos, incluso IG y DO nacionales o extranjeras, ha sido admitido no solo en la República Argentina, sino en otros países como EE.UU. donde la DO Tequila (instrumentada como marca de certificación) ha coexistido con alrededor de 270 marcas conformadas por el mismo topónimo ${ }^{22}$. También, en Brasil se ha admitido la coexistencia de marcas e IG o DO (Mónaco, Champagne) ${ }^{23}$.

La validez de estas marcas en Argentina, depende de que hayan sido registradas de buena fe con anterioridad a la aplicación del Acuerdo ADPIC.

\subsection{LA JURISPRUDENCIA ARGENTINA SOBRE MARCAS (CONFORMADAS POR NOMBRES GEOGRÁFICOS) ANTERIOR A LA APROBACIÓN DE LOS CONVENIOS INTERNACIONALES SOBRE PROPIEDAD INTELECTUAL E INDUSTRIAL \\ Para comprender la situación vigente del régimen de marcas en la República Argen-} tina a la fecha de entrada en vigor del Acuerdo ADPIC, debe tenerse en cuenta la evolución de la jurisprudencia marcaria, en relación a los nombres geográficos en general, DO e IG.

Hasta la fecha de entrada en vigencia del Acuerdo ADPIC y la sanción de las Leyes Nacionales $\mathrm{N}^{\circ} 25.163$ y $\mathrm{N}^{\circ} 25.380$ no se había protegido ni registrado ninguna IG o DO nacional. Numerosos nombres geográficos estaban registrados como marca; por tanto, no se podían registrar como DO o IG, a pesar de identificar un área de producción renombrada.

En la jurisprudencia marcaria, pueden distinguirse distintas etapas.

\subsubsection{Primera etapa, comprendida entre la sanción de la primera Ley de Marcas $N^{\circ}$} $787^{24}$ (año 1876) hasta la sanción de la Ley $N^{\circ} 17.011$ que aprobó el Convenio de Paris de 1883 y sus revisiones posteriores.

Las antiguas Leyes $\mathrm{N}^{\circ} 787$ y $\mathrm{N}^{\circ} 3.975^{25}$-hoy derogadas- no prohibieron la registración de IP, DO (en esa fecha la República Argentina no había ratificado el Convenio de París de 1883) ni en general de los nombres geográficos, como marcas. Solo se excluyó el nombre y letras del Estado, en virtud de lo dispuesto por el art. 3 inciso 1 de la Ley $N^{\circ}$ 787. Esta ley no aclaraba si se refería al Estado Nacional, o se extendía a los nombres de las provincias. La Corte Suprema de Justicia de la Nación (CSJN) sostuvo que la prohibición legal "se refiere a las letras, nombres distintivos del Estado para distinguir las cosas oficiales, pasando ante los ojos de todos como emanadas del Gobierno"26.

Dentro de ese marco normativo, la jurisprudencia admitió ampliamente la registración de nombres geográficos como signo marcario, salvo excepciones aisladas ${ }^{27}$.

En esa línea, la Cámara Federal Civil y Comercial consideró que "los nombres geográficos podían ser registrados como marcas, a menos que fuesen de uso común, partiendo

22 GANGJEe (2007) p. 1261.

23 Sousa Borda (2015) pp. 11-12.

24 LEY N 787 de 1876.

25 LEY $\mathrm{N}^{\circ} 3.975$ de 1900.

26 CSJN Argentina: ECHEMERDI CON SEMINARIO (1895).

27 CSJN Argentina: LARROQUETTE CON TAPIA (1912). 
del principio que la registrabilidad es la regla y la irregistrabilidad la excepción..."28 Interpretó que los topónimos son marcariamente débiles y no monopolizables por una sola persona; por tanto, sus titulares no pueden impedir la registración de signos complejos, integrados por la palabra de uso común y otro término figurativo que torne inconfundible el conjunto (in re "Melman Sulim" ${ }^{29}$ ) salvo que se induzca a confusión al consumidor.

\subsubsection{Segunda etapa comprendida entre la sanción de la Ley $N^{\circ} 17.011$ y el inicio de la} aplicación del Acuerdo ADPIC en la República Argentina.

En 1966 se sancionó la Ley №17.011 que aprobó el Convenio de París de 1883.

Dieciséis años más tarde se sancionó la Ley $\mathrm{N}^{\circ} 22.362^{30}$ de "Marcas"; poco después, la Ley $\mathrm{N}^{\circ} 22.802^{31}$ de "Lealtad comercial". Ambas normas prohibieron registrar un nombre geográfico como marca cuando constituye una DO o produce confusión en el consumidor acerca del origen del producto. Estas normas solamente definieron la DO pero no establecieron un régimen especial; tampoco mencionaron la IP a pesar de estar prevista en el citado Convenio.

Por tanto, en el ordenamiento jurídico argentino de ese período, la DO estuvo protegida dentro del régimen general de competencia desleal. Los titulares de una DO extranjera (en esa fecha no había DO nacionales protegidas) podían oponerse al registro como marca y solicitar el cese de uso cuando daba lugar a confusión en el consumidor sobre el origen y la calidad del producto.

La jurisprudencia continuó admitiendo como principio general, la registrabilidad de los nombres geográficos, fundándose entre tres argumentos:

En primer lugar, hicieron una interpretación gramatical del art.3 inc.c) de la Ley $\mathrm{N}^{\circ} 22.362$ y arts.7 y 8 de la Ley $\mathrm{N}^{\circ} 22.802$ que solo prohibía registrar una DO.

En segundo término, interpretaron restrictivamente la prohibición del art. 3 incs. f) y g) de la Ley $\mathrm{N}^{\circ} 22.362$, entendiendo que se refería a nombres y distintivos oficiales del Estado.

En tercer lugar, la jurisprudencia continuó interpretando que el nombre geográfico es de uso común no monopolizable, pero podía integrar un conjunto marcario si existen elementos inconfundibles.

En esta línea argumental, la Cámara Nacional Civil y Comercial rechazó la oposición de la marca Panamá, por entender que: "Los nombres geográficos pueden ser registrados como marcas, a menos que sean denominaciones de origen o de uso común debiéndose tener presente que la registrabilidad es la regla y la no registrabilidad la excepción ${ }^{32}$.

La CSJN confirmó una sentencia que había rechazado la oposición a la registración de la marca Kiedrich diciendo que "corresponde descartar el eventual perjuicio contra la República Alemana respecto de su industria vitivinícola por la concesión del uso de la mar-

28 CNac.Apelac.Civil y Comercial, Sala II, Argentina: LEBEDINSKY CON CERAMICAS SUDAMERICANA SRL (1970).

29 CNac.Apelac. Civil y Comercial, Argentina: MELman Sulim HNOS CON SUTER Y CIA SRL (1959).

30 LEY N 22.362 de 1980.

31 LEY N 22.802 de 1983.

32 CNac.Apelac.Civil y Comercial Sala II, Argentina: THE SCOTCH WHISKY Association CON GARCÍ (2000). 
ca "Kiedrich-comarca de ese país- (...) a cuyo fin requieren que sobre los envases o envoltorios o sobre los mismos objetos se imprima la expresión "industria argentina”33.

En sentido contrario, la CSJN confirmó la sentencia de Cámara que había rechazado la registración de la marca "Tinogasteña" ${ }^{4}$ (localidad de la Provincia de Catamarca), interpretando que el gentilicio era indicativo del lugar de origen del producto y podía confundir al consumidor.

Por su parte, la Cámara Nacional dijo en relación a una marca conformada por la DO Saint Emilion" 35 :La marca que caducó y cuya renovación se intenta es una copia de la denominación existente en Francia desde 1935. Las hipótesis de aprovechamiento indebido de una marca o de un nombre ajenos ha sido normalmente encuadrados en el art. 935 del Código Civil, cuya razón de ser resulta de la necesidad de sancionar a los supuestos de plagio de marcas extranjeras, con la posibilidad de adueñarse así del prestigio adquirido por productos identificados por ellas".

En el mismo sentido, dijo en relación a la marca "Nuestro Bianchi Margaux" conformada por la DO "Margaux" "36: "Conforme con lo prescripto en el inc. c) del art. 30 de la Ley de Marcas No 22.362, no pueden ser registras las denominaciones de origen nacionales o extranjeras (...) El decreto de la República Francesa del 17.8.54 establece que Margaux es una DOC...", por tanto, no puede ser registrada como marca.

En esta etapa no hubo oposiciones por parte de los titulares de las marcas conformadas por el nombre geográfico San Rafael y Luján, en relación a las DOC integradas con el mismo toponímico, protegidas en el marco de la Ley $\mathrm{N}^{\circ} 5.999^{37}$ de la Provincia de Mendoza.

\subsubsection{Tercera etapa, posterior al comienzo de aplicación del Acuerdo ADPIC en la Argentina ${ }^{38}$.}

La jurisprudencia de la Cámara Federal mantuvo el mismo criterio de épocas anteriores, admitiendo la registrabilidad de los nombres geográficos como regla (ya sean nombres geográficos extranjeros (Monza ${ }^{39}$ o Delicia Suiza ${ }^{40}$ ), nacionales (Chocolate Bariloche ${ }^{41}$ ) o nacionales y extranjeros, y como excepción la irregistrabilidad. En consecuencia, los

33 CSJN Argentina: STABILISIERUNGSFOND FUR WEIN CON BODEGAS ESMERALDA SA (1986).

34 CSJN Argentina: BODEGAS Y VIÑEDOS SANTIAGO GRAFFIGNA LTDA SA CON INV (1977).

35 CNac.Apelac. Civil y Comercial, Sala I, Argentina: Institut National des ApPelLations d'origine CON Resia (1990).

36 CNac.Apelac. Civil y Comercial, Sala III, Argentina: VALENTín BIANCHI SACI CON INSTituto NATIONAL DES APPELLATIONS D'ORIGINE (1989).

37 LEY No 5.999 (Mendoza) de 1993.

38 Debe distinguirse fecha de entrada en vigor y fecha de aplicación del Acuerdo ADPIC. Este Acuerdo entró en vigencia en la Argentina el 13/1/1995, pero podía aplazar su aplicación (art. 65 incs.1 y 2). "La República Argentina es un país en desarrollo, por tanto, la obligatoriedad de la aplicación de todas sus disposiciones podía quedar diferida por cinco años (un año de dilación común para todos los países y cuatro para los países en desarrollo), computados desde la entrada en vigor de la LeY N²4.425”, Molina (2015) p. 76.

39 CNac.Apelac.Civil y Comercial, Sala I, Argentina: General Motors Corporation Con FeIJoo (2002).

40 CNac.Apelac.Civil y Comercial, Sala II, Argentina: GourmesA SA CON CHOCOSUISSE (2003).

41 CNac.Apelac.Civil y Comercial, Sala III, Argentina: Chocolates BARILOCHE SAIC (2005). 
nombres geográficos pueden ser registrados como marcas, en tanto no hayan sido registrados y protegidos como una DO, IG o sean de uso común ${ }^{42}$ (criterio prevaleciente en la doctrina y jurisprudencia de otros países latinoamericanos ${ }^{43}$ ).

La Cámara Federal dijo in re "Punta Godoy" que: "Los nombres geográficos pueden ser registrados como marcas, a menos que sean DO o de uso común debiéndose tener presente que la registrabilidad es la regla y la no registrabilidad la excepción. La DO es un nombre geográfico que ha venido a ser el nombre de un producto, el cual por provenir de esa zona geográfica, tiene características propias y, por ende, distintas de otras de la misma especie provenientes de otros lugares (...) las denominaciones de productos que individualizan el lugar de procedencia (La Rioja o el Riojano para identificar vinos de esa zona) constituyen elementos de uso común en la clase respectiva determinando que dichas voces sean insusceptibles de ser monopolizadas por persona alguna..." 44

Ese fallo no tuvo en cuenta que "Rioja" es una DO española, tal vez porque no fue parte el Consejo Regulador de esa DO. Además el nombre geográfico "La Rioja argentina" estaba incluido en el padrón básico aprobado mediante Resolución INV.C23/99 ${ }^{45}$.

Pocos meses después de esa sentencia, la IG "Rioja argentina” fue reconocida mediante Resolución INV.C.32/02 ${ }^{46}$. Esa resolución fue impugnada por el Consejo Regulador Rioja (España) dando lugar a un proceso judicial. En ese proceso, la Cámara rechazó la impugnación confirmando la resolución emitida por la autoridad administrativa ${ }^{47}$. Posteriormente, la sentencia fue confirmada por la $\mathrm{CSJN}^{48}$.

\subsection{LaS MARCAS E INDICACIONES DE ORIGEN GEOGRÁFICO A PARTIR DE LA SANCIÓN DE} LAS LEYES $\mathrm{N}^{\circ} 25.163$ Y N $\mathrm{N}^{\circ} 25.380$

La solución jurídica a los conflictos entre las marcas y las indicaciones de origen geográfico depende del sistema jurídico adoptado por cada Estado para su protección (régimen de marcas colectivas o certificación, competencia desleal, categoría sui generis, régimen de patrimonio cultural o de dominio público).

Las Leyes argentinas $\mathrm{N}^{\circ} 25.163$ y $\mathrm{N}^{\circ} 25.380$ adoptaron un régimen sui generis de protección de las indicaciones de origen geográfico, quedando subsistente subsidiariamente el régimen de competencia desleal con carácter residual para las situaciones de conflicto no reguladas expresamente (signos distintivos notorios, indicaciones de procedencia de productos agroalimentarios que induzcan a error, etc.).

A partir de la vigencia de esos textos legales (art. 46 inc.b de la Ley $N^{\circ} 25.163$ para vinos y art. 43 inc.b de la Ley $\mathrm{N}^{\circ} 25.380$ para los demás productos agroalimentarios), no

\footnotetext{
42 Bertone y Cabanellas de las Cuevas (2003) T.I, p.314 y 383-386; Otamendi (2002) p. 55; Schiavone (2003) p. 25.

43 Tinoco Soares (2008) p. 328.

44 CNac.Apelac. Civil y Comercial, Sala III, Argentina: PUNTA GodoY SRL CON Bodegas de LA RIoJA SA. (2001).

45 Resolución INV C.23 de 1999.

46 Resolución INV C32 de 2002.

47 Juzgado Fed.Cont.Adm.N²4, Argentina: CONSEJO REGULADOR DOC RIOJA CON INV (2011).

48 CSJN Argentina: CONSEJO REGULADOR DOC RIOJA CON INV (2015).
} 
pueden registrarse como marca una IG, DO (DOC para vinos) e IP (solo para vinos) sin perjuicio de los derechos adquiridos en relación a marcas registradas de buena fe a la fecha de la aplicación del Acuerdo ADPIC.

Ambas leyes tardaron en aplicarse ante la demora en su reglamentación. La Ley $\mathrm{N}^{\circ} 25.163$ fue reglamentada mediante Decreto $\mathrm{N}^{\circ} 57 / 04^{49}$. El Decreto $\mathrm{N}^{\circ} 556 / 09^{50}$ reglamentó la Ley $\mathrm{N}^{\circ} 25.380$.

En el lapso anterior a la emisión del decreto reglamentario de la Ley $\mathrm{N}^{\circ} 25.163$, el Instituto Nacional de Vitivinicultura (INV) dictó resoluciones con el fin de paliar los vacíos normativos. Entre ellas, emitió la Resolución C.23/99 por la que estableció el "Padrón básico de áreas geográficas" aptas para acceder a una DOC y una IG.

La inclusión de un área geográfica en esa nómina, implicó la consideración de su aptitud para el reconocimiento y registro de una indicación de origen geográfico, pero no significó su afectación automática al régimen de la Ley $\mathrm{N}^{\circ} 25.163$, ni la creación de un nuevo signo distintivo.

La Ley $\mathrm{N}^{\circ} 22.362$ ha adoptado el sistema atributivo para la adquisición del derecho exclusivo sobre la marca. Mediante este sistema, se atribuye el derecho a quien obtiene el registro ${ }^{51}$.

La Resolución INV.C23/99 es un acto administrativo general que debía ajustarse a las leyes, por tanto, no podía modificar la prioridad establecida en la Ley $\mathrm{N}^{\circ}$ 22.362. Tampoco, la Administración puede reconocer de oficio una DO, toda vez que esta debe ser solicitada por los productores agrupados en una asociación civil.

Entonces, ¿`cuál es el efecto jurídico del padrón de áreas geográficas?

La marca confiere el derecho de explotación exclusiva y el ius prohibendi, siempre que hubiere sido registrada de buena $\mathrm{fe}^{52}$. La registración de una marca conformada por un topónimo incluido en el padrón básico de áreas geográficas no puede reputarse de buena fe, toda vez que el peticionante debía conocer la vigencia de la Resolución INV.C.23/99 que había sido publicada en el Boletín Oficial.

\subsection{LA RECEPCIÓN JURISPRUdENCIAL DE LA PROTECCIÓN DE LA IG}

En la causa judicial "FINCA FLICHMAN SA"33", la Cámara hizo lugar al recurso de apelación revocando la sentencia de primera instancia que había admitido el registro de la marca "Paisajes de Tupungato".

La sentencia tuvo en cuenta la vigencia del Acuerdo ADPIC en la República Argentina, la sanción de la Ley N²5.163, y la emisión de la Resolución INV.C.32/02 que reconoció el nombre geográfico "Tupungato" (zona productora de vinos renombrada) como Indicación Geográfica (IG).

\footnotetext{
49 DeCreto nacional N ${ }^{\circ} 57$ de 2004.

50 Decreto nacional $\mathrm{N}^{\circ} 559$ de 2009.

51 Otamendi (2002) p. 13; Bertone y Cabanellas de las Cuevas (2003) pp. 335-345.

52 Otamendi (2002) pp. 11-12.

53 CNac.Apelac. Civil y Comercial, Sala I, Argentina: FINCA FLICHMAN SA CON INPI (2013).
} 
En sus fundamentos, la sentencia expresó que el Acuerdo ADPIC declara inválidas aquellas marcas "posteriores a la aplicación de las normas del ADPIC para ese Estado miembro, o antes que la IG estuviera protegida en su país de origen”. La solicitud de registro de la marca Tupungato presentada por FINCA FLICHMAN SA era posterior a la entrada en vigencia del Acuerdo ADPIC, por tanto, no podía admitirse su registro, independientemente que hubieran marcas registradas con el mismo toponímico cuya titularidad pertenecía a terceros. El fallo, dejó a salvo el derecho de la actora de usar ese nombre geográfico como IG, por cuanto el INV le había concedido el derecho de uso de la IG Tupungato, por tratarse de un establecimiento vitivinícola que cosecha y produce vinos en esa área geográfica.

Este fallo, dio un paso en la protección de la IG. Hasta entonces, la jurisprudencia argentina se había limitado a efectivizar la protección de la DO según un concepto restringido, olvidando otras categorías de indicaciones de origen geográfico reconocidas por el Convenio de París de 1883 y el Acuerdo ADPIC (ratificados por la Ley No $17.011^{54}$ y $N^{\circ} 24.425$, respectivamente). Sin embargo, la Cámara Federal limitó los efectos de esa protección, al enrolarse en una postura negatoria de la IG como objeto de propiedad intelectual.

\section{APLICABILIDAD DE LOS PRINCIPIOS MARCARIOS A LAS INDICACIONES DE ORIGEN GEOGRÁFICOS}

\subsection{Principios de prioridad y eXClusividad VERSUS COEXISTENCIA DE Signos Distintivos (MARCAS E IG, DO)}

En el derecho argentino, la propiedad de la marca y la exclusividad de su uso, se obtiene con su registro de buena fe en el INPI. El derecho de prelación para la propiedad de la marca, se determina por el día y hora en que se presente la solicitud (arts. 4 y 8 de la Ley $\mathrm{N}^{\circ}$ 22.362). Este es el principio de prioridad ("primero en el tiempo, primero en el derecho").

El art.3 de la Ley $\mathrm{N}^{\circ} 22.362$ prohíbe el registro de DO como marcas (también, art.46 inc.b) Ley No 25.163 y art.43 inc.b) de la Ley No 25.380). Por su parte, el art.32 inc.c) de la Ley $\mathrm{N}^{\circ} 25.163$ y art.25 inc.b) de la Ley $\mathrm{N}^{\circ} 25.380$, prohíben el reconocimiento de marcas vigentes como DO (DOC para vinos), IG e IP (esta última, para vinos).

El art.24 inc.5 del Acuerdo ADPIC prevé expresamente la aplicación del principio de prioridad a los conflictos de las marcas con indicaciones de origen geográfico.

Sin embargo, dicho principio no rige frente a DO o IG renombradas por aplicación de las reglas de la competencia desleal (que analizaremos en el pto 5.1); además, hay casos en que debe admitirse la coexistencia.

Hay supuestos de coexistencia que surgen del Acuerdo ADPIC (algunos para DO e IG entre sí); otros, han sido admitidos por la legislación nacional y otros se desprenden de la jurisprudencia argentina en materia marcaria.

54 Sancionada el 10/11/1966; publicada en el BO N² 21068 del 17/11/1966. 
En primer lugar, el art.23 inc.3 del Acuerdo ADPIC admite la coexistencia de IG y DO de vinos en los casos de homonimia. Ese artículo dispone que: "En el caso de IGs homónimas para los vinos, la protección se concederá a cada indicación (...) Cada Miembro establecerá las condiciones prácticas en que se diferenciarán entre sí las indicaciones homónimas de que se trate, teniendo en cuenta la necesidad de asegurarse de que los productores interesados reciban un trato equitativo y que los consumidores no sean inducidos a error". Esa protección tiene el límite previsto en el art.22 inc.4) respecto de las indicaciones de origen geográfico verdaderas en cuanto al territorio de origen pero que dé al público la idea falsa de que se originan en otro territorio.

Esa disposición del Acuerdo ADPIC ha establecido una regla mínima para zanjar situaciones conflictivas de DO e IG homónimas de distintos países cuya solución queda sujeta a los ordenamientos jurídicos nacionales que abordan el conflicto de distinta manera.

Muchos conflictos hoy subsisten y han trascendido los límites de los países directamente involucrados como los casos de IG Lemberg (Sudáfrica) vs IG St.Magdalena am Lemberg (Austria), la DO Pisco Perú vs DO Pisco Chile; DO Rioja (España) vs IG La Rioja Argentina, etc.

En algunos casos, los Superiores Tribunales de algunos Estados signatarios se han expedido sobre estos conflictos. En otros casos, los Estados involucrados han obtenido el reconocimiento y protección mediante acuerdos bilaterales o multilaterales, cuyo análisis excede el objetivo del presente trabajo.

Solamente mencionaremos que el INV ha aplicado el art.23 inc.3 del Acuerdo ADPIC, admitiendo el registro de IG homónimas nacionales para los vinos (IG San MartínMendoza; San Martín-San Juan; IG San Carlos-Mendoza e IG San Carlos-Salta) aún frente a la existencia de numerosas marcas homónimas. También, admitió el registro de la IG La Rioja Argentina sin cuestionamiento por parte de los titulares de las marcas Rioja, Gran Riojano y otras similares, pero con la oposición del Consejo Regulador de la DO Rioja (España), luego rechazada por la CSJN 55 .

A los fines de evitar la confusión del consumidor, el INV dictó la Resolución C.20/04 para los vinos, que establece características tipográficas y tamaños distintos, y diferente ubicación en el etiquetado según se trate de IP, IG o DOC.

Cabe preguntarse si esta regla para indicaciones de origen geográfico homónimas puede aplicarse a conflictos entre IG y marcas homónimas renombradas de vinos, teniendo en cuenta que en el derecho comparado algunos ordenamientos jurídicos regulan la IG dentro del régimen marcario (marcas colectivas o certificación). Entendemos, que deben aplicarse esas reglas en relación a indicaciones de origen geográfico instrumentadas mediante marcas de certificación o colectivas en el marco de su legislación nacional.

En segundo lugar, el caso de coexistencia admitido por el INV. La Ley N²5.163 no ha prohibido expresamente la coexistencia de distintas categorías de indicaciones de origen geográfico para vinos homónimas. Frente a este vacío normativo, el INV ha admitido la coexistencia de la IG y DOC Luján y DOC e IG San Rafael, siendo además nombres geográficos que integran numerosas marcas.

55 CSJN Argentina: CONSEJO REGULADOR DOC RIOJA CON INV (2015). 
La interpretación del INV se ha apartado del criterio predominante en el derecho comparado europeo, que exige para el reconocimiento de una DO, que previamente haya sido reconocida y protegida como IG, debiendo permanecer en dicha categoría por varios años. Después de 5 años, los productores pueden solicitar la protección como DO. Luego de transcurridos 10 años pueden solicitar la protección como DO Calificada ${ }^{56}$. Los nombres geográficos protegidos en cada nivel no pueden ser utilizados para la designación de otros productos vitivinícolas.

En cambio, el art.16 de la Ley $\mathrm{N}^{\circ} 25.380$ y su modificatoria Ley $\mathrm{N}^{\circ} 25.966$, dispone expresamente que el reconocimiento de una DO constituida por un nombre geográfico que identifique una IG, produce de inmediato la cancelación de esta última.

Esa norma jurídica no admite la coexistencia de una DO e IG constituida por el mismo nombre geográfico sobre el mismo producto.

En tercer lugar, hay casos de coexistencia de marcas conformadas por el mismo nombre geográfico (considerado como elemento de uso común no monopolizable), admitidos por la jurisprudencia argentina. Esa jurisprudencia puede aplicarse para resolver conflictos de las marcas con otros signos distintivos.

En estos casos, el titular de una marca constituida por un nombre geográfico no puede oponerse a que otro la registre como DO (DOC para vinos), IG o IP (solo para vinos) siempre que se agregue algún elemento que evite la confusión del consumidor.

No obstante, el Decreto reglamentario N $57 / 04$ prevé para el registro de una IG y DOC, el consentimiento expreso y escrito de los titulares de las marcas conformadas por el mismo topónimo. Esta exigencia dificulta innecesariamente el trámite registral de la DO o IG cuyos topónimos conforman numerosas marcas, siendo que los titulares no podrían oponerse exitosamente al registro de aquellas conforme la jurisprudencia argentina.

En cuarto lugar, también hemos manifestado que hay numerosas marcas registradas integradas por algunas DO que han pasado a ser nombre genéricos en la República Argentina (Jerez, Champagne, etc.). Los titulares de esas marcas tampoco podrían impedir el posterior registro de DO extranjeras en nuwestro país salvo confusión en el consumidor. En este caso, también deberá admitirse la coexistencia de marca y DO.

Más allá de lo expuesto, son innumerables los conflictos que no quedan comprendidos en las soluciones normativas, como aquellos referidos a las marcas notorias y una DO o IG renombradas; tampoco, se ha previsto una solución a los conflictos entre las marcas registradas y una DO o IG ampliamente usadas en un Estado signatario antes de la aplicación del Acuerdo ADPIC.

Algunos autores extranjeros han propuesto criterios flexibles para la solución de estos conflictos como la notoriedad del signo, tiempo de uso o directamente la coexistencia, siempre que se exija el cumplimiento de ciertas medidas para evitar la confusión en el consumidor $^{57}$.

Algunos países, han seguido este criterio flexible y han convenido mediante acuerdos bilaterales o multilaterales la protección de DO nacionales, incluyendo algún signo homó-

56 Arts. 22 inc. 2 y 23 inc. 1 de la LeY N 24 (España) de 2003.

57 Stern (2003) pp. 12-13; Gangjee (2007) pp. 1289-1291; Carraou (2006) pp. 350-351. 
nimo. Mediante este mecanismo, se ha obtenido la coexistencia de DO e IG homónimas en esos países; también, de marcas y DO o IG.

La República Argentina no ha suscripto convenios bilaterales o multilaterales a ese fin. La coexistencia puede ser admitida siempre que se prevean ciertas exigencias para evitar la confusión del consumidor excepto en dos situaciones. Primero, cuando se induce a error al consumidor sobre el origen geográfico. Segundo, en los casos de competencia desleal por aplicación de las reglas del Convenio de París de 1883 (aprovechamiento indebido del prestigio de un signo distintivo) y el art. 22 inc. 2 del Acuerdo ADPIC.

Estas situaciones fácticas deben ser probadas en cada caso y su valoración está librada a la apreciación judicial conforme al ordenamiento jurídico interno de cada Estado.

\subsection{LA EXTENSIÓN DE LA PROTECCIÓN A VOCABLOS QUE CONTIENEN LA INDICACIÓN DE ORIGEN GEOGRÁFICO Y EL PRINCIPIO DE VERACIDAD}

Debemos recordar que en el sistema marcario son condiciones para el registro de la marca: el carácter distintivo del signo y su disponibilidad. La propiedad de la marca confiere el derecho de oponerse al registro y uso de otra marca conformada por el mismo o por vocablos confundibles.

La doctrina y la jurisprudencia argentina han elaborado diversas pautas para determinar su confundibilidad, ya entre los mismos o diferentes productos. Entre los mismos productos puede haber confusión visual, auditiva (fonética, siglas), ideológica (conceptual, idioma extranjero y traducción, etc.). Aún entre marcas para distintos productos, la jurisprudencia ha interpretado que pueden ser confundibles cuando corresponden al mismo género de producto, emplean la misma materia prima, se usan conjuntamente o tienen la misma finalidad o se venden en el mismo negocio ${ }^{58}$.

En relación a la IG, el Acuerdo ADPIC prevé reglas específicas. La extensión de la protección sobre el topónimo y sus variantes depende si se trata de una DO o IG de vinos o de otros productos.

En el primer caso (vinos), debe denegarse o invalidarse la marca que "consista o contenga" una IG siempre que el producto provenga de una región distinta del verdadero lugar de origen, independientemente que induzca a confusión en el consumidor.

En relación a los vinos, el art.23 inc. 2 del Acuerdo ADPIC dispone que: "De oficio, si la legislación de un Miembro lo permite, o a petición de una parte interesada, el registro de toda marca de fábrica o de comercio para vinos que contenga o consista en una indicación geográfica que identifique vinos, o para bebidas espirituosas que contenga o consista en una indicación geográfica que identifique bebidas espirituosas, se denegará o invalidará para los vinos o las bebidas espirituosas que no tengan ese origen”.

Esta disposición recepta el principio de veracidad aplicable exclusivamente a las IGs de vinos independientemente que induzca a error en el consumidor, y se extiende a las marcas que están conformadas o contienen una IG.

En relación a un conflicto de una marca e IG (para identificar vinos), el Tribunal General de la Unión Europea recientemente ha dicho que “...el signo solicitado, Lember-

58 Otamendi (2002) pp. 141-171. 
gerland, es una palabra compuesta, en particular, por la indicación geográfica protegida Lemberg, que es claramente identificable dentro de ese signo (...) el registro de una marca debe denegarse si esta contiene o está compuesta de una indicación geográfica independientemente de si el signo solicitado puede inducir a error al consumidor en lo que respecta al origen de los vinos que designa (...) sin que proceda tener en cuenta si la marca cuyo registro se solicita puede o no inducir a error al público o si conlleva un riesgo de confusión para este por lo que respecta al origen del producto" 59 .

En esa misma línea, el Tribunal Superior de España confirmó la denegatoria de registro de la marca "Lambrusco dell'Emilia Canottieri" por incluir alguno de los elementos de las denominaciones de origen protegidas ("Lambrusco Grasparossa di Castelvetro", "Lambrusco Salamino di S. Croce" y "Lambrusco di Sorbara") $)^{60}$, también de la marca Valdouro ${ }^{61}$ y Durius Alto Duero ${ }^{62}$, estas dos últimas por incluir la DO Ribera del Duero. En estos casos, se trató de conflictos entre marcas e IG o DO para vinos.

En el segundo caso (conflictos entre una marca e IG para los demás productos), es indispensable probar que se induce al público a error.

El art.22 inc.2.a) dispone que podrá impedirse "la utilización de cualquier medio que, en la designación o presentación del producto, indique o sugiera que el producto de que se trate proviene de una región geográfica distinta del verdadero lugar de origen, de modo que induzca al público a error en cuanto al origen geográfico del producto”. Es decir, debe probarse el riesgo de confusión en el caso concreto.

El Tribunal General de Justicia de la Unión Europea, en las sentencias del 9 de junio de $1998^{63}$ y 28 de enero de $1999^{64}$ interpretó que cuando se utiliza como marca uno de los componentes de una DO "no basta con comprobar que una marca que contiene una palabra que figura en la designación de uno de los productos mencionados en dicha disposición puede, por sí misma, ser confundida con esta designación. Es preciso, además, demostrar que, de hecho, la utilización de la marca puede inducir a error a los consumidores de que se trate $y$, por consiguiente, puede afectar a su comportamiento económico. A este respecto, el Juez nacional debe atenerse a la presunta expectativa que, sobre esta indicación, tenga el consumidor medio, normalmente informado y razonablemente atento y perspicaz".

Recientemente, el Tribunal General de la Unión Europea se ha expedido sobre el riesgo de confusión de una DO para vinos (Porto, Port u Oporto) y la marca Port Charlotte para whisky considerando que se trataban de productos diferentes y que además, la palabra Porto o Port designa un sustantivo (puerto) pudiendo referirse a innumerables ciudades de distintos países como Porto Alegre, Port Louis, etc ${ }^{65}$.

59 TG Unión Europea: GENOSSENSCHAFTSKELLEREI ROSSWAG-MÜHLHAUSEN VERSUS OAMI (2015).

60 TS España: Consorzio per la tUtela DeI Vini RegGiano e Colli Di SCANdiano (2014).

61 TS España: LES GRANDS CHAIS DE FRANCE, S.A (2008).

62 TS España: Bodegas Durius Alto Duero versus Consejo Regulador de la Denominación de Origen Ribera DEL DUERO (2009).

63 TJ Unión Europea: YVON CHICIAK Y FROMAGERIE CHICIAK (1998).

64 TJ Unión Europea: VERBRAUCHERSCHUTZVEREIN VERSUS KESSLER (1999).

65 TG Unión Europea: Instituto dos Vinhos do Douro e do Porto Versus OAMI (2015). 
En la República Argentina, no hemos encontrado antecedentes jurisprudenciales que hayan invalidado marcas por aplicación del principio de veracidad.

Esas disposiciones del citado Acuerdo tienen un límite y consecuencias en el derecho argentino. Primero, la prescriptibilidad de la acción de nulidad (art.25 de la Ley N²2.362 y art.6 bis inc. 2 del Convenio de París de 1883 aunque esta exceptúa el registro de mala fe). Segundo, la responsabilidad del Estado por acto legislativo (modificación del régimen jurídico de propiedad intelectual) en tanto produzca un daño cierto y determinado o imponga un sacrificio desigual en perjuicio de una persona.

\subsection{El principio de especialidad. Su aplicabilidad o no a las indicaciones de ORIGEN GEOGRÁFICO}

En el Derecho de Marcas rige el principio de especialidad por el cual la exclusividad del derecho de un signo marcario se extiende solo a los productos respecto de los cuales fue registrado, por tanto, pueden coexistir marcas similares o idénticas cuando se utilizan en productos o servicios distintos.

¿Rige el principio de especialidad en relación a las indicaciones de origen geográfico?

El Documento SCT 5/3 ha señalado que la IG está sujeta al principio de especialidad.

Entendemos que este principio, es una regla general para todos los signos distintivos; por tanto, se aplica a las indicaciones de origen geográfico. Criterio receptado por la doctrina $\operatorname{argentina}{ }^{66}$.

3.4. LOS PRINCIPIOS, NORMAS Y JURISPRUDENCIA SOBRE MARCAS NOTORIAS. SU APLICABILIDAD O NO A LAS INDICACIONES DE ORIGEN GEOGRÁFICO

Una marca notoria es conocida por gran parte de los consumidores, identificándola con un producto determinado.

La marca notoria goza de un status especial en el derecho marcario. Hay normas y pautas jurisprudenciales aplicables a estas, frente a eventuales usurpaciones y por lo general ante la ausencia de registro o renovación. Esta protección se justifica además, para evitar la pérdida de su capacidad distintiva ${ }^{67}$.

La jurisprudencia argentina ha sostenido en las causas judiciales "Staton", "Chevron" ${ }^{68}$ que el principio de especialidad cede frente a los supuestos de conflictos de marcas notorias.

En la causa "Staton" dijo que: “...el titular de una marca notoria tiene interés legítimo en que su signo no sea utilizado por otros en productos diferentes, puesto que ello provocaría la dilución de la marca, su poder distintivo que es lo más valioso de ella, bien entendido que el carácter notorio de una marca es una categoría de excepción y que debe ser reconocida con carácter restrictivo ceñido solo a los supuestos de signos de amplia ex-

\footnotetext{
${ }^{66}$ Isturiz de GuYot y Félix (1996) pp. 135-141

67 Otamendi (2002) p. 353

68 CNac.Apelac. Civil y Comercial, Sala II, Argentina: CHEVRON U.S.A con LA FARMACo ARGENTINA INDUSTRIAL Y COMERCIAL SA (1990)
} 
plotación y difusión (...) una marca puede ser calificada de notoria si ella es conocida por una gran fracción del público, es decir por el conjunto de la población, confluyendo tres aspectos para que se dé la notoriedad, la antigüedad de la marca, su empleo extendido y un esfuerzo publicitario importante (...) Es que, a la postre, la dilución o erosión del poder distintivo de la marca -particularmente si esta es notoria- le resta una de sus principales, o cuando menos le deteriore, su papel publicitario y esto apareja, como natural consecuencia, el debilitamiento de su valor de venta (...) de su texto resulta la obligación de proteger la marca notoria por ser tal, con independencia de que distinga productos de naturaleza idéntica o diferente" 69 .

El art. 6 bis del Convenio de París de 1883 previó que los Estados miembros debían brindar amparo a las marcas notoriamente conocidas en el país en el que se reclama protección. El Acuerdo ADPIC brinda amparo inclusive cuando la notoriedad sea en otro país miembro como consecuencia de su promoción y aun cuando no hayan sido registradas, siempre que el uso indique una conexión entre dichos productos y su uso lesione los derechos del titular.

¿Se aplican las reglas y jurisprudencia de las marcas notorias a las indicaciones de origen geográfico?

La DO y la IG identifican productos con tipicidad y originalidad reconocidas por el consumidor. El reconocimiento y protección de la DO no es un mero acto estatal de creación, sino de confirmación y ratificación de una designación geográfica que identifica un producto afamado en el mercado. Una característica de la DO es su prestigio y fama ${ }^{70}$, pudiendo devenir fácilmente en genéricas.

La OMPI ha dicho que: “...la protección internacional de las IGs notoriamente conocidas contra su utilización no autorizada en productos distintos, no se ha desarrollado de la misma manera que en relación a las marcas, aunque se conoce desde hace tiempo la existencia del problema”. El conflicto con IG y DO ha sido especialmente tratado en el Symposium on the International Protection of Geographical Indications, WIPO, Melbourne de 1995, pero no ha habido una recepción expresa en una norma internacional.

No obstante, el uso no autorizado de una IG renombrada aprovecha o va en detrimento de la reputación de esta, por tanto constituye un acto de competencia desleal"71.

La jurisprudencia europea está evolucionando hacia una protección amplia de la IG y DO renombradas (particularmente de vinos), entendiendo que la protección se extiende no solo a los productos de la misma clase (Ej. Margaux para vinos ${ }^{72}$ ) sino a todas las clases del Nomenclador; abarcando el topónimo y en algunos casos, sus variantes ${ }^{73}$.

Este criterio tiende a preservar el carácter distintivo del signo, evitando la vulgarización y pérdida del carácter distintivo del nombre geográfico.

69 CNac.Apelac. Civil y Comercial, Sala III, Argentina: STANTON S.A CON INPI (2002).

70 Bonet (2004) pp. 853-862.

71 Comité Permanente sobre el Derecho de Marcas, Dibujos y Modelos industriales e Indicaciones GeoGRÁFICAS, OMPI (2000): Documento SCT 5/3, párrafos 20 y 58.

72 Álvarez (2004) pp. 373-377.

73 Bonet (2004) p. 853; Álvarez (2004) pp. 373-377; Molina (2015) pp. 72-74. 
En la República Argentina, la jurisprudencia ha prescindido del principio de especialidad cuando el uso de una DO en productos de otra clase del Nomenclador puede confundir al consumidor, pero sin mencionar las reglas de las marcas notorias.

En este sentido, in re "Pontet" rechazó el registro de la marca Jerez, Oporto y Vermouth para mermeladas (clase 29) en tanto corresponde a una DO para vinos (clase 33), diciendo que: "La clase 29 abarca comestibles entre ellos, las mermeladas que comercializan los actores, que se venden en los mismos almacenes y comercios pequeños en los que se pueden encontrar bebidas alcohólicas. La experiencia -que es de un indudable valor en materia marcaria, así lo demuestra-, de tal modo que es razonable arribar a la conclusión de que el público consumidor se puede llegar a confundir respecto de la procedencia u origen de las mermeladas que llevan el mismo nombre que el Oporto, el Jerez o el Vermouth que fabrica la demandada" 74 .

En definitiva, esta sentencia aplicó las reglas de la competencia desleal.

Propugnamos la aplicación de las reglas de las marcas notorias no solo para protegerlas del uso indebido y preservar su prestigio sino también, para evitar su vulgarización y pérdida de su capacidad distintiva.

\section{CONFLICTO ENTRE MARCA ARGENTINA E INDICACIONES DE ORIGEN GEOGRÁFICO EXTRANJERAS}

\subsection{Principios receptados en el Acuerdo ADPIC}

En el conflicto entre la marca argentina e IG o DO extranjeras, prevalece la marca nacional sobre la indicación de origen geográfico extranjera siempre que se prueben los siguientes presupuestos:

Primero, que haya sido registrada o haya sido usada de buena fe. En el derecho argentino el derecho de propiedad y la exclusividad de la marca se adquiere con el registro, por tanto, no puede invocarse la prioridad por el mero uso del signo, salvo notoriedad. La solución legal surge de la interpretación armónica de los arts.4 y 8 de la Ley $\mathrm{N}^{\circ} 22.362$ y art.24 párr.5 del Acuerdo ADPIC.

Segundo, que el registro sea anterior a la protección legal de la IG. El art.24 inc.5 de ese Acuerdo, consagra la prioridad de la marca si fue registrada o se presentó su solicitud: a) antes de la fecha de aplicación del Acuerdo ADPIC en ese miembro; b) antes de que la indicación de origen geográfico estuviera protegida en su país de origen”.

Tercero, la marca registrada debe haber sido usada en los últimos cinco años. De lo contrario, toda persona interesada (entre ellos, el titular de una IG o DO extranjera) puede solicitar la caducidad. El uso de la marca es un requisito para la conservación del derecho marcario, no solo para evitar que la marca caduque sino también para poder renovarla a su vencimiento (arts. 5 “in fine” y 26 de la Ley $N^{\circ} 22.362$ ).

74 CNac.Apelac. Civil y Comercial, Sala I, Argentina: PONTET CON SAENZ BRIONES SAIC (1995). 
La Cámara Nacional en lo Civil y Comercial in re "Peters"75 tuvo oportunidad de expedirse en relación a un conflicto entre una marca nacional y una DO europea no registrada en nuestro país. La Cámara confirmó la sentencia de primera instancia que rechazó la demanda promovida por Peters Hnos. SA contra el Institut National d'appellations d'origine, declarando fundada la oposición al registro de la marca "Martinique" para identificar productos de la clase 33. El Tribunal ponderó que la marca se había extinguido por vencimiento del plazo en 1996 sin ser renovada. Tampoco se había acreditado uso de la marca con posterioridad al vencimiento del plazo (período 1996-2000).

Textualmente dijo que: "la actora no ejerció su derecho de renovación, ni en tiempo oportuno ni en tiempo razonable posterior. Esto trajo la consecuencia de que el titular de la marca perdió sus derechos conforme el régimen atributivo de la ley. A partir de entonces el valor de su signo debe compatibilizarse con otras circunstancias fácticas y jurídicas concomitantes a estos hechos, entre ellas, la vigencia para la República Argentina del Acuerdo ADPIC (...) Asimismo, un aspecto fáctico relevante es que la DO "Martinique" fue reconocida oficialmente en Francia por Decreto del 5/11/1996..."

Debe tenerse en cuenta, que la legislación argentina no prevé la registración obligatoria de una IG ni DO extranjera ante los organismos nacionales para el ejercicio de las acciones judiciales ${ }^{76}$, previendo solamente una registración facultativa (art.38 inc.d del Decreto $\mathrm{N}^{\circ} 57 / 04$ para los vinos y art.23 de la Ley $\mathrm{N}^{\circ} 25.380$ ).

De ese modo, se ha establecido un sistema complejo y dual de registro de la indicación de origen geográfico cuyo análisis excede los objetivos del presente artículo. Solamente señalamos, que la IG y DO extranjeras renombradas y no registradas pero usadas en la República Argentina, gozan de protección legal.

Sin embargo, queda un amplio vacío normativo en cuanto al alcance de esa protección. Ya hemos mencionado que la jurisprudencia argentina no ha aplicado hasta la fecha las reglas de las marcas notorias a la DO afamada sino que ha aplicado las normas de competencia desleal. Por tanto, ha quedado sujeto a la decisión judicial la valoración del aprovechamiento indebido del prestigio de una $\mathrm{DO}$ o la inducción de confusión en el consumidor en cada caso concreto.

\subsection{Principio De territorialidad y los acuerdos bilaterales y multilaterales en EL MARCO DEL ACUERDo ADPIC \\ El principio de territorialidad significa que la protección del signo distintivo se con-} fiere dentro del ámbito del Estado donde se ha registrado y usado.

Este principio se aplica a la IG y DO. Por tanto, una IG puede ser considerada como tal en un Estado mientras que en otro, el topónimo puede estar registrado como una marca o constituir una expresión genérica de productos ${ }^{77}$.

\footnotetext{
75 CNac.Apelac. Civil y Comercial, Sala I, Argentina: Peters HNos CISA cON INSTITUT NATIONAL DES ApPeLLATIONS D'ORIGINE (2010).

76 García Sellart (2003) p. 60.

77 Comité sobre el Derecho de marcas, dibujos y modelos industriales e indicaciones geográficas, OMPI (2000): Documento SCT 5/3, parágrafos 21 y 55.
} 
Los Estados signatarios del Acuerdo ADPIC se comprometieron a ampliar la protección de una indicación de origen geográfico para vinos dentro de su ámbito interno mediante acuerdos bilaterales o multilaterales con el Estado de origen (art.23), aunque también pueden usar facultativamente estos convenios para ampliar la protección en relación a los demás productos.

Esa mayor protección puede colisionar con el derecho de propiedad sobre las marcas registradas cuando está integrada por un nombre geográfico que también conforma una DO.

En el derecho argentino, más allá de las distintas acepciones del término "propiedad" receptada en el art.17 de la Constitución Nacional, la CSJN en un viejo fallo ${ }^{78}$ extendió dicha noción a todos los derechos, ya sean reales o personales, materiales e inmateriales, susceptibles de apreciación pecuniaria cuando existe una acción judicial para su defensa. Criterio mantenido en los fallos posteriores.

En ese concepto amplio de propiedad, queda incluida la propiedad de la marca. La Ley $\mathrm{N}^{\circ} 22.362$ se refiere en varias disposiciones a la propiedad de la marca y el titular dispone de acciones judiciales para impedir su uso o reivindicarla.

Por ello, si la República Argentina suscribiese acuerdos de esa naturaleza, deberá dejar a salvo los derechos adquiridos respecto de las marcas registradas de buena fe con anterioridad a la aplicación del Acuerdo ADPIC, siempre que hubieren sido usadas en los últimos cinco años, o deberá proceder a la expropiación de la marca previa calificación de utilidad pública por el Poder Legislativo e indemnización.

Sin embargo, la noción de utilidad pública comprende los casos de satisfacción del bien común, el progreso y bienestar de la comunidad ${ }^{79}$. No puede expropiarse para la satisfacción de un bien privado.

Además, debe tenerse en cuenta la situación actual de las marcas vigentes en la República Argentina para no emitir actos irrazonables. Un sinnúmero de ellas están conformadas por nombres geográficos, algunos DO o IG. No resultaría razonable expropiar una decena y, en algunos casos, una centena de marcas complejas conformadas por el mismo toponímico, cuando pueden coexistir conforme la jurisprudencia argentina.

\section{EL DESARROLLO DEL SISTEMA DE LAS INDICACIONES DE ORIGEN GEOGRÁFICO Y LAS SOLUCIONES A LOS CONFLICTOS ADOPTADAS POR SUS TITULARES}

Ya mencionamos que las marcas registradas en el marco de la legislación vigente a la fecha en que empezó a aplicarse el Acuerdo ADPIC constituyó un límite a la protección de la IG y DO extranjeras. También mencionamos que es una peculiaridad del régimen marcario argentino, la gran cantidad de marcas conformadas por nombres geográficos, algunos DO e IG.

78 CSJN Argentina: BOURDIEU CON MUNICIPALIDAD DE CAPITAL (1925).

79 CSJN Argentina: SERVICIO NACIONAL de PARQUes NACIONALES CON FRANZINI (1995). 
A pesar del compromiso asumido por los Estados signatarios del Acuerdo ADPIC de ampliar la protección de la IG para vinos mediante acuerdos bilaterales y multilaterales, la República Argentina hasta la fecha no ha suscripto ninguno con esa finalidad.

Lo cierto es que ha habido una clara tendencia de los titulares de DO en buscar soluciones dentro del sistema marcario, aprovechando la jurisprudencia argentina que considera el nombre geográfico como un elemento de uso común no monopolizable.

En ese sentido, la DOC San Rafael y DOC Luján solicitaron su reconocimiento y protección en el marco de la Ley $\mathrm{N}^{\circ}$ 25.163. Sin embargo, el Consejo de DO de cada una, obtuvo también el registro a su nombre de la marca homónima sin oposición de los numerosos titulares de marcas complejas conformadas por el mismo topónimo.

Algunas indicaciones de origen extranjeras siguieron el mismo camino pero con algunas notas peculiares. En general, no han solicitado el reconocimiento y registro en el marco de las Leyes $\mathrm{N}^{\circ} 25.163$ y $\mathrm{N}^{\circ} 25.380$ y su modificatoria. Las leyes argentinas no imponen la obligación de registrar la DO e IG extranjeras para su defensa judicial.

Las agrupaciones de productores del área geográfica optaron por registrar la DO como marca.

Entre ellas, la Societe Civile Agricole Chateau Margaux obtuvo el registro de la marca Margaux coexistiendo con unas pocas marcas vigentes conformadas por el mismo nombre geográfico. Por su parte, el Consorzio per la Tutela dei vini Reggiano e Colli Di Scandiano obtuvo el registro de la marca Lambrusco coexistiendo con dos marcas complejas integradas por el mismo topónimo. La Scea Du Chateau La Coste obtuvo el registro de la marca La Provence coexistiendo con varias marcas complejas conformadas con el mismo topónimo. El Consorzio del Formaggio Parmigiano Reggiano registró como marca la designación reggiano coexistiendo con otras dos marcas complejas integradas por la misma designación.

El caso más paradigmático ha sido la defensa de la DO Roquefort. La Confederation Generale des Producteurs de Lait de Brebis et des Industriels de Roquefort obtuvo el registro de la marca roquefort, siendo actualmente la única titular de una marca con esa designación en todas las clases del Nomenclador. Sin embargo, durante años, coexistieron varias marcas integradas por esa DO que había devenido en el nombre habitual del producto en nuestro país.

Frente a este panorama pueden intentarse dos explicaciones:

Primero, el régimen marcario (ampliamente arraigado en la República Argentina) ha ofrecido mayores garantías para la defensa de la IG y DO extranjeras. Especialmente, se ha tenido en cuenta la jurisprudencia argentina que ha receptado una postura favorable a la protección de las marcas notorias, pero no así de la DO o IG renombradas, a las cuales se les ha aplicado excepcionalmente las reglas de la competencia desleal.

Segundo, la jurisprudencia argentina no concibe la DO o IG como objeto de propiedad intelectual ni le reconoce exclusividad en el uso. Esta postura negatoria ha sido receptada en la causa judicial "Flichman" ${ }^{0}$ fundándose en las singularidades, defectos y omisiones del sistema argentino. Frente a ese panorama del régimen de indicaciones de origen geográfico, la marca confiere el derecho de exclusividad y garantiza su defensa contra el uso indebido.

80 CNac.Apelac. Civil y Comercial, Sala I, Argentina: FINCA FLICHMAN SA CON INPI (2013). 


\section{CONCLUSIONES}

La jurisprudencia argentina sobre los conflictos entre las marcas e indicaciones de origen geográfico (especialmente sobre la IG) es incipiente. En general, no ha mencionado expresamente los principios marcarios para resolver estos conflictos ni las reglas de las marcas notorias, aunque el resultado ha sido equivalente.

Tampoco ha mencionado el principio de veracidad receptado por el Acuerdo ADPIC aplicable exclusivamente a las indicaciones de origen geográfico de vinos. Todo ello, parece despertar desconfianza de algunos titulares de DO e IG extranjeras, quienes han buscado la defensa de ese signo distintivo dentro del régimen de marcas.

Veremos si en los próximos años la jurisprudencia argentina consolida una protección amplia de la DO e IG.

A ese fin, proponemos las siguientes reglas de interpretación:

Primero, aplicación del principio de especialidad con la adaptación que exige el Acuerdo ADPIC.

Segundo, aplicación de las reglas de las marcas notorias a las indicaciones de origen geográfico para proteger no solo el signo renombrado frente al uso indebido por terceros, sino también para prevenir su vulgarización y la dilución de su capacidad distintiva.

Tercero, aplicación del principio de veracidad. En relación a los vinos, debe denegarse o invalidarse la marca que consista o contenga una IG o DO siempre que el producto provenga de una región distinta del verdadero lugar de origen independientemente que induzca a confusión al consumidor. En relación a los demás productos, debe probarse que el signo puede inducir a error en el consumidor.

Cuarto, aplicación del principio de prioridad, por tanto, prevalece el signo que primero haya sido registrado de buena fe. Esa prioridad no podrá imponerse frente a una IG o DO extranjera usada ampliamente en el país. La legislación argentina no exige la registración obligatoria de las indicaciones de origen extranjeras para el ejercicio de acciones judiciales En dicho caso, debe autorizarse la coexistencia de ambos signos distintivos siempre que no se provoque confusión en el consumidor.

Quinto, admitir la coexistencia en los casos de homonimia admitidos por el Acuerdo ADPIC, por la legislación argentina (marcas e indicaciones de origen geográfico extranjeras usadas pero no registradas en la República Argentina), por la jurisprudencia argentina que ha considerado el topónimo como elemento débil del signo marcario; por último, aquellos casos admitidos por acuerdos bilaterales y multilaterales.

\section{BIBLIOGRAFÍA CITADA}

Álvarez Enríquez, Carmen (2004): "Rechazo de denominaciones de origen como marcas comerciales", Revista Chilena de Derecho, vol.31, N²: pp. 373-377.

Belmar Gamboa, Carolina (2016): "Las denominaciones de origen en Chile: desarrollo y perspectivas”, RIVAR, vol. 3, No 8: pp. 253-266.

Bertone, Luis y Cabanellas de las Cuevas, Guillermo (2003): Derecho de Marcas, Tomo I (Buenos Aires, Editorial Heliasta). 
Bonet, Georges (2004): "Des cigarettes aux parfums, Irrésistible ascension de l'appellation d'origine Champagne vers la protection absolue", Propriétés intellectuelles, $\mathrm{N}^{\circ} 13$, France: pp. 853-862.

CARRAU, Javier Guillem (2006): Denominaciones geográficas en el Derecho de la Unión Europea y de la Organización Mundial de Comercio (Valencia, Universidad de Valencia, Editor Tirant lo Blanch).

Gangjee, Dev (2007): "Quibbling Siblings: Conflicts between Trademarks and Geographical Indications”, Chicago-Kent Law Review, vol. 82, Issue 3: pp.1252-1291.

García Sellart, Marcelo (2003): "Algunas reflexiones sobre el régimen legal de las indicaciones geográficas en la Argentina”, Derechos Intelectuales Tomo 10 (Buenos Aires, Editorial Astrea) pp. 39-64.

Isturiz de GuYot, María Elena y FéLIX, Norma (1996): "Las marcas y las denominaciones de origen", en Primer Seminario sobre denominación de origen (Buenos Aires, Ministerio de Economía de la Nación) pp. 135-141.

Molina, Marcela (2015): "Las designaciones de origen geográfico extranjeras que pasaron al uso común para designar un tipo de producto en el derecho argentino", Revista Iberoamericana de Viticultura, Agroindustria y Ruralidad, vol.2, No 5: pp. 64-82. Disponible en: http:www.rivar.usach.cl. Fecha consulta: 20 de diciembre de 2015.

OMPI, Comité Permanente sobre el Derecho de Marcas, Dibujos y Modelos industriales e Indicaciones Geográficas (2000): Documento SCT 5/3, 5º sesión, 11 a (15 de septiembre 2000). Disponible en: http:www.wipo.int/portal/es. Fecha de consulta: 1 de abril de 2016.

OMPI, Comité Permanente sobre derecho de maras, dibujos y modelos industriales E INDICACIONES GEOGRÁfICAS (2002): Documento SCT 9/4, 9ºsesión, 11 a (15 de noviembre de 2002). Disponible en: hppt:www.wipo.int/portal/es. Fecha de consulta: 1 de abril de 2016.

OMPI, Comité Permanente sobre Derechos de marcas, dibujos y modelos industriales E INDICACIONES GEOGRÁFICAS (2003): Documento SCT 10/4, 10a sesión (28 de abril al 2 de mayo de 2003). Disponible en: http:www.wipo.int/portal/es. Fecha de consulta: 1 de abril de 2016.

Otamend, Jorge (2002): Derecho de Marcas (Buenos Aires, Editorial LexisNexis, cuarta edición actualizada).

PASTORINO, Leonardo (2005): La política europea de desarrollo rural sostenible ¡obstáculo o modelo para el Mercosur? (Buenos Aires, Colecciones Éxtasis Ediciones al margen).

Schiavone, Elena (2003): “Indicaciones geográficas", Derechos intelectuales, Tomo 10, (Buenos Aires, Editorial Astrea) pp.15-38.

Sousa Borda, Ana Lúcia de (2015): "Denominaciones de origen en Brasil: situación actual. Su desarrollo: jurisprudencia y avances de los productores", RIVAR, vol. 2, No 5: p.1-21. Disponible en: http:www.rivar.usach.cl. Fecha consulta: 20 de diciembre de 2015.

STERN S. (2003): "Geographical indications and trade marks: conflicts and possible resolutions" en Worldwide Symposium on Geographical Indications (San Francisco, California). Disponible en http://www.wipo.int/edocs/mdocs/geoind. Fecha de consulta: 30 de enero de 2016. 
Tinoco Soares, José (2008): Tratado de propiedad industrial de las Américas: marcas y congéneres (Buenos Aires, Editorial LexisNexis).

\section{NORMAS CITADAS}

\section{Argentina}

Ley naCional Nº 787 (19/8/1876), Norma de Marcas.

LeY naCiOnal Nº 3.975 (23/11/1900), Norma de Marcas.

Ley nacional Nº 17.011 (17/11/1966), aprueba Convenio de París de 1883.

LEY NACIONAL $N^{\circ} 22.802$ (11/5/1983), Norma de Lealtad Comercial.

LEY NACIONAL No $22.362(2 / 1 / 1981)$, Norma de Marcas.

LeY de Mendoza No 5.999 (18/5/1993).

LeY naCional No 24.425 (5/1/1995), aprueba Acuerdo ADPIC.

LEY NACIONAL No 25.163 (12/10/1999), Norma sobre designación de los vinos por su origen.

ReSOLUCión INV C.23 (29/12/1999).

LEY NACIONAL N 25.380 (12/1/2001), Régimen legal para IP y DO de productos agrícolas y alimentarios.

ResOlución INV C.32 (25/11/2002).

Decreto nacional No $57(14 / 1 / 2004)$.

LEY NACIONAL $\mathrm{N}^{\circ} 25.966(21 / 12 / 2004)$, modificatoria de la Ley $\mathrm{N}^{\circ} 25.380$.

LeY de Misiones No VIII-51 (N 4.298) (23/6/2006).

DeCreto NACIONAL $\mathrm{N}^{\circ} 1.384(27 / 8 / 2008)$.

Decreto nacional No $556(15 / 5 / 2009)$.

URUGUAY

LEy N ${ }^{\circ} 17.011$ (15/9/1998), Norma de Marcas.

BRASIL

LeY N 9.279 (14/5/1996), Norma de Propiedad Industrial.

ESPAÑA

LEY Nº 24 (11/7/2003), Norma sobre la Viña y el Vino.

\section{JURISPRUDENCIA CITADA}

ARgENTINA

Echemerdi de Seminario, Juana con Carlos Seminario (1895): Corte Suprema de Justicia de la Nación, 20 de febrero de 1895 (falsificación marca), Fallos, Tomo 60: pp. 231-243.

Bourdieu, Pedro con Municipalidad de CAPITAL (1925): Corte Suprema de Justicia de la Nación, 16 de diciembre de 1925 (reintegro suma de dinero), Fallos, Tomo 145: p. 307-383. 
Melman Sulim Hnos con Suter y CÍA SRL(1959): Cámara Nacional de Apelaciones de Capital Federal, 9 de junio de 1959. Disponible en: http:www.jurisprudencia.pjn.gov.ar. Fecha de consulta: 30 de julio de 2015.

LEBEDINSKY CON CERAMICAS SUDAMERICANA SRL (1970): Cámara Nacional de Apelaciones Federal, Sala II, 4/12/1970, Revista El Derecho, Tomo 41: pp.185-203.

Bodegas y ViñEdos Santiago GRafFigna Ltda SA con Instituto Nacional de VitiVinicultu$R A$ (1977): Corte Suprema de Justicia de la Nación, 15 de septiembre de 1977 (revocatoria de resolución), Fallos, Tomo 298: p. 681-685.

STABILISIERUNGSFOND FUR WEIN CON BODEGAS ESPERALDA SA (1986): Corte Suprema de Justicia de la Nación, 10 de abril de 1986, Fallos, Tomo 308, pp. 536-538.

Valentín Bianchi SACI con Instituto National des Appellations d’origine (1989) Cámara Nacional Apelaciones Civil y Comercial Federal, Sala III, 25 de agosto de 1989 (oposición registro de marca). Disponible en:http:www.pjn.gov.ar. Fecha de consulta: 30 de julio de 2015.

Chevron U.S.A con La Farmaco Argentina Industrial y Comercial SA (1990): Cámara Civ.Com.Fed., Sala II, 22 de mayo de 1990 (cese de oposición registro marca). Disponible en: http:www.jurisprudencia.pjn.gov.ar. Fecha de consulta: 30 de julio de 2015.

Institut National des Appellations d'origine con Resia, Hugo (1990): Cámara Nac.Apelac.Civil y Comercial Federal, Sala 1, 14 de junio de 1990 (acción de nulidad). Disponible en: http:www.pjn.gov.ar. Fecha de consulta: 30 de julio de 2015.

Pontet, OMAR con SAENZ BRIONES SAIC (1995): Cámara Nacional de Apelaciones Civil y Comercial, Sala I, 26 de septiembre de 1995 (cese oposición registro de marca). Disponible en: http:www.jurisprudencia.pjn.gov.ar. Fecha de consulta: 30 de julio de 2015.

Servicio Nacional de Parques Nacionales con Franzini, Carlos (1995): Corte Suprema de Justicia de la Nación, 5 de abril de 1995 (expropiación), Fallos, Tomo 318, p. 445-470.

The SCOTCH Whisky Association con GARCÍA, José (2000) Cámara Nacional de Apelaciones Civil y Comercial, Sala II, 15 de febrero de 2000 (cese oposición registro marca). Disponible en: http:www.juriprudencia.pjn.gov.ar. Fecha de consulta: 30 de julio de 2015.

Punta Godoy SRL con Bodegas de LA RIOJA SA (2001): Cámara Nacional de Apelaciones Civil y Comercial, Sala III, 13 de noviembre de 2001, Revista La Ley, Tomo 2002-B: p. 760 .

General Motors Corporation con Feijoo, José (2002): Cámara Nacional de Apelaciones Civil y Comercial, Sala I, 25 de junio de 2002 (cese oposición registro de marca). Disponible en: http:www.jurisprudencia.pjn.gov.ar. Fecha de consulta: 24 de julio de 2015.

Stanton \& Cía. S.A con Instituto de la PRopiedad Industrial (2002): Cámara Civil Comercial Federal, Sala III, 21 de marzo de 2002. Disponible en: http:www.jurisprudencia.pjn.gov.ar. Fecha de consulta: 30 de julio de 2015.

Gourmesa SA CON ChOCOSUISSE UNIÓN DE FABRICANTES SUIZOS DE CHOCOLATE (2003): Cámara Nacional de Apelaciones Civil y Comercial, Sala II, 25 de junio de 2003 (cese oposición registro de marca). Disponible en: http:www.juriprudencia.pjn.gov.ar. Fecha de consulta: 30 de julio de 2015.

Chocolates Bariloche SAIC con Fenoglio SA (2005): Cámara Nacional de Apelaciones Civil y Comercial, Sala III, 14 de junio de 2005 (cese oposición registro marca). Disponible en: http:www.jurisprudencia.pjn.gov.ar. Fecha de consulta: 30 de julio de 2015. 
Peters Hnos CiSA con Institut National des Appellations d’origine (2010): Cámara Nacional de Apelaciones Civil y Comercial, Sala I, 12 de agosto de 2010. Disponible en: http:www.jurisprudencia.pjn.gov.ar. Fecha de consulta: 30 de julio de 2015.

Consejo Regulador DOC Rioja Y OtRo con Instituto NACional de VitiVinicultura (2011): Juzgado Nacional Contencioso Administrativo Federal N 4, 24 de febrero de 2011 (proceso de conocimiento), Revista El Derecho T² 242: pp. 401-405.

LaRroquette, JuAN con TAPiA, LEONCIO (1912): Corte Suprema de Justicia de la Nación, 3 de septiembre de 1912 (imitación fraudulenta de marca), Fallos, Tomo 116: p. 30-35.

Finca Flichman SA con Instituto Nacional de Propiedad Intelectual (2013): Cámara Nacional Apelaciones Civil y Comercial, Sala I, 21 de mayo de 2013 (denegatoria registro de marca). Disponible en: http:www.ijeditores.com.ar. Fecha de consulta: 24 de julio de 2015.

Consejo Regulador DOC Rioja y otro con Instituto NaCional de Vitivinicultura (2015), Corte Suprema de Justicia de la Nación, 29 de diciembre de 2015 (proceso de conocimiento). Disponible en: http:www.csj.gov.ar. Fecha consulta: 20 de julio de 2015.

ESPAÑA

LES GRANDS ChaIS DE FRANCE SA (2008): Tribunal Supremo Sala III de lo Contencioso Administrativo, 15 de octubre de 2008 (denegación de marca). Disponible en: http:www. poderjudicial.es/cgpj/es/Poder-Judicial/Tribunal-Supremo. Fecha de consulta: 20 de abril de 2016.

Bodegas Durius Alto Duero (2009): Tribunal Supremo Sala III de lo Contencioso Administrativo, 5 de mayo de 2009. Disponible en:http:www.poderjudicial.es/cgpj/es/. Fecha de consulta: 20 de abril de 2016.

Consorcio per la tutela Del Vini Reggioano e Colli Di Scandiano e Di Canossa y el Consorcio Tutela del Lambrusco Di Modena (2014): Tribunal Supremo, Sala de lo Contencioso, 6 de octubre de 2014. Disponible en: http:www.poderjudicial.es/cgpj/es/ Poder-Judicial/Tribunal-Supremo. Fecha de consulta: 20 de abril de 2016.

UNIÓN EUROPEA

YVON CHICIAK Y Fromagerie ChICIAK (1998): Tribunal de Justicia, 9 de junio de 1998. Disponible en: http:curia.europa.eu/jcms/jcms. Fecha de consulta: 20 de abril de 2016.

VerbRAUCHERSCHUtZVEREIN VERSUS SEKTKELLEREI G. C. KESSLER GMBH und Co. (1999): Tribunal de Justicia, Sala V, 28 de enero de 1999. Disponible en: http:curia.europa.eu/jcms/ jcms. Fecha de consulta: 20 de abril de 2016.

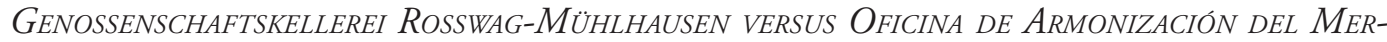
CADO INTERIOR (Marcas, Dibujos y Modelos) (OAMI) (2015): Tribunal General, Sala I, 14 de julio de 2015, ECLI EU, Tomo 2015, p.486. Disponible en: http:curia.europa. eu/jcms/jcms. Fecha de consulta: 20 de abril de 2016.

instituto dos Vinhos do Douro e do Porto versus Oficina de Armonización del Mercado INTERIOR (OAMI) (2015): Tribunal General, Sala IV, 18 de noviembre de 2015 (nulidad de marca comunitaria). Disponible en: http://curia.europa.eu/jcms/jcms. Fecha de consulta: 20 de abril de 2016 . 